
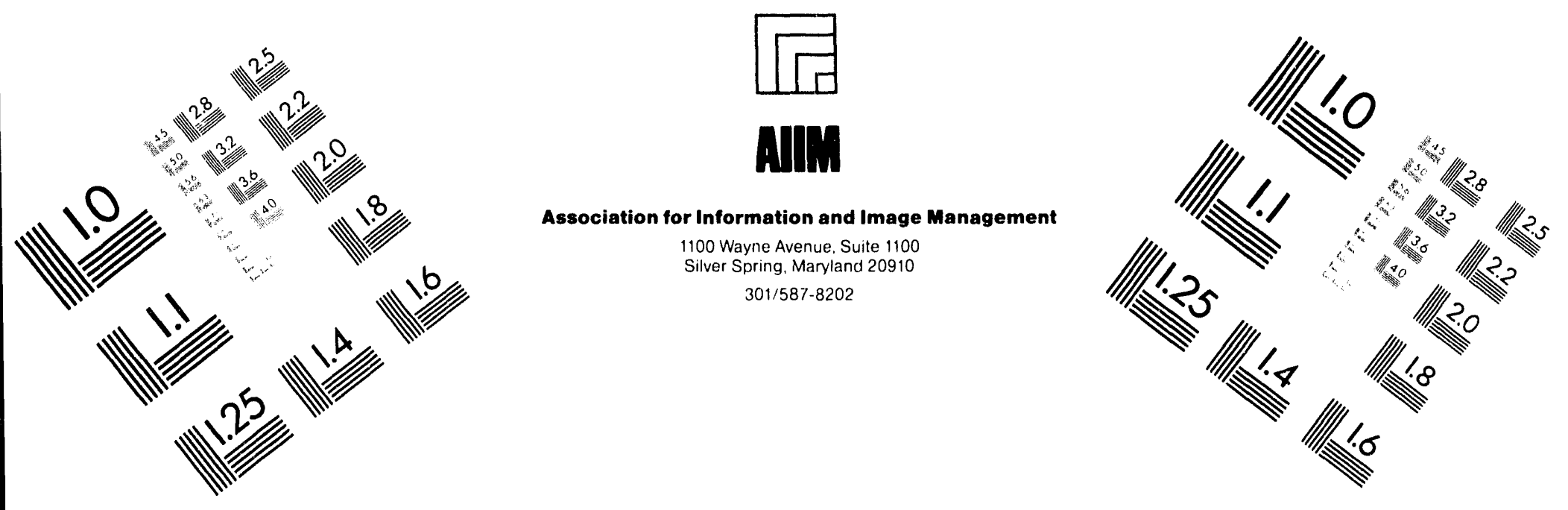

\title{
Centimeter
}

1
$\mid$

Inches
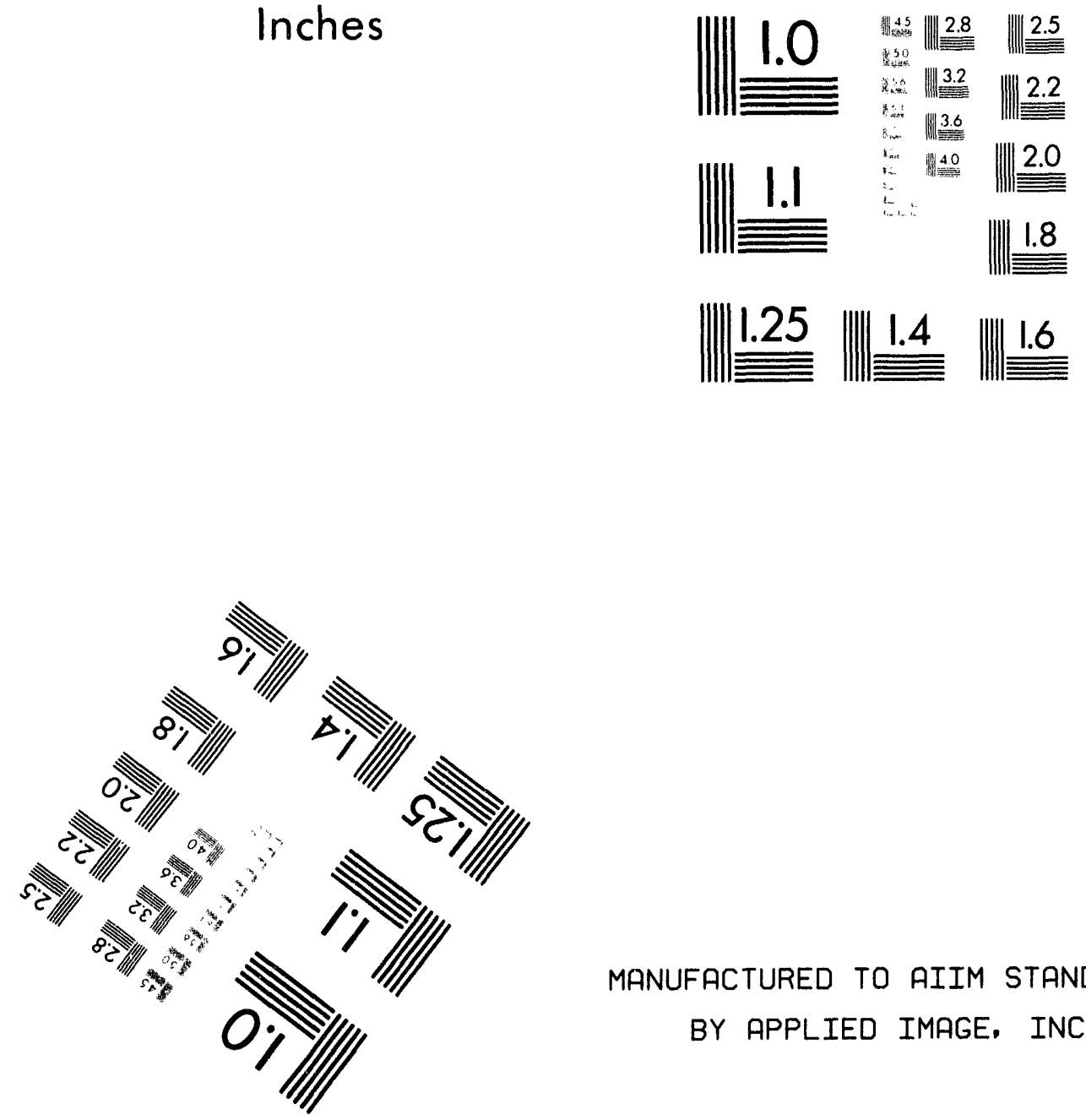

MANUFACTURED TO AIIM STANDARDS

BY APPLIED IMAGE. INC.

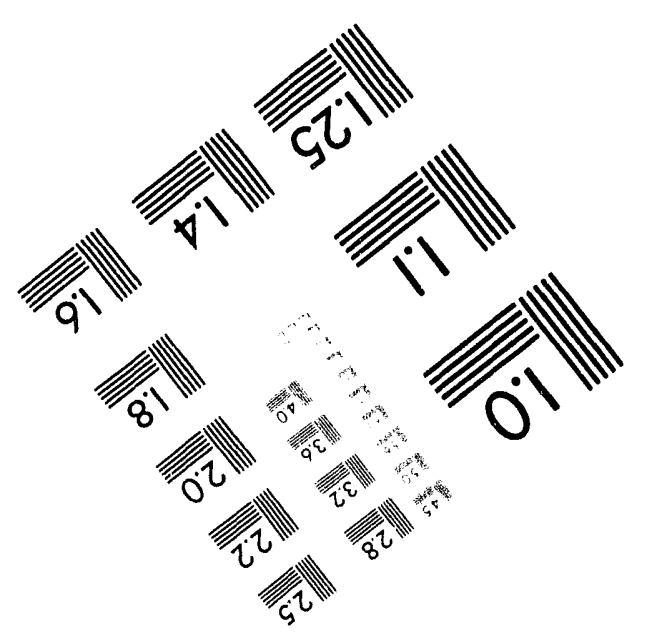



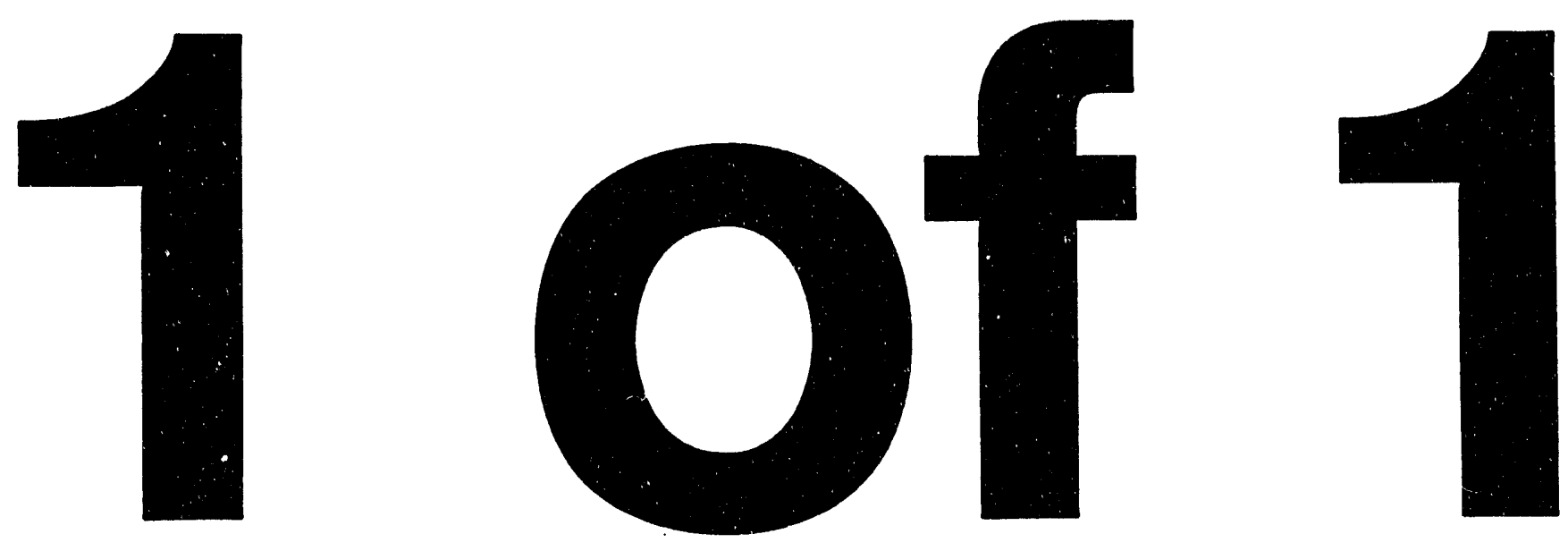
HAM PRD ATOMIC PRQDUCTS OPERATION - RIOHRISGEIWABHINGTON … COPY NO. AND SERIES

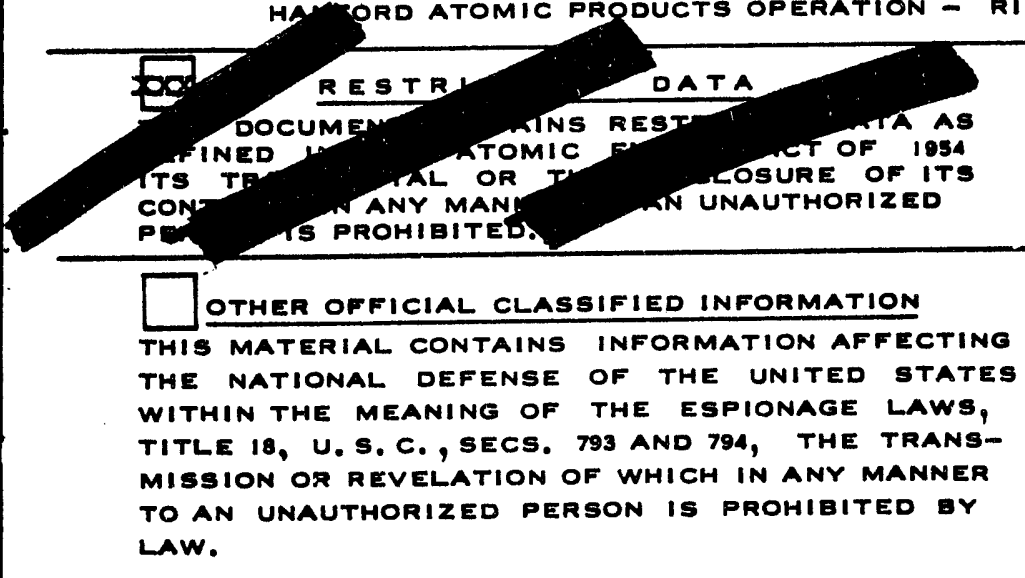 FILE DESIGNATION
FEIUnV 10 TITLE

Altermative Actions on The K Stack Problem THIS MATERIAL CONTAINS INFORMATION AFFECTING THE NATIONAL DEFENSE OF THE UNITED STATES TITLE 18, U. S. C., SECS. 793 AND 794, THE TRANSMISSION OR REVELATION OF WHICH IN ANY MANNER LAW.

\section{Complled by:}

H. G. Spencer
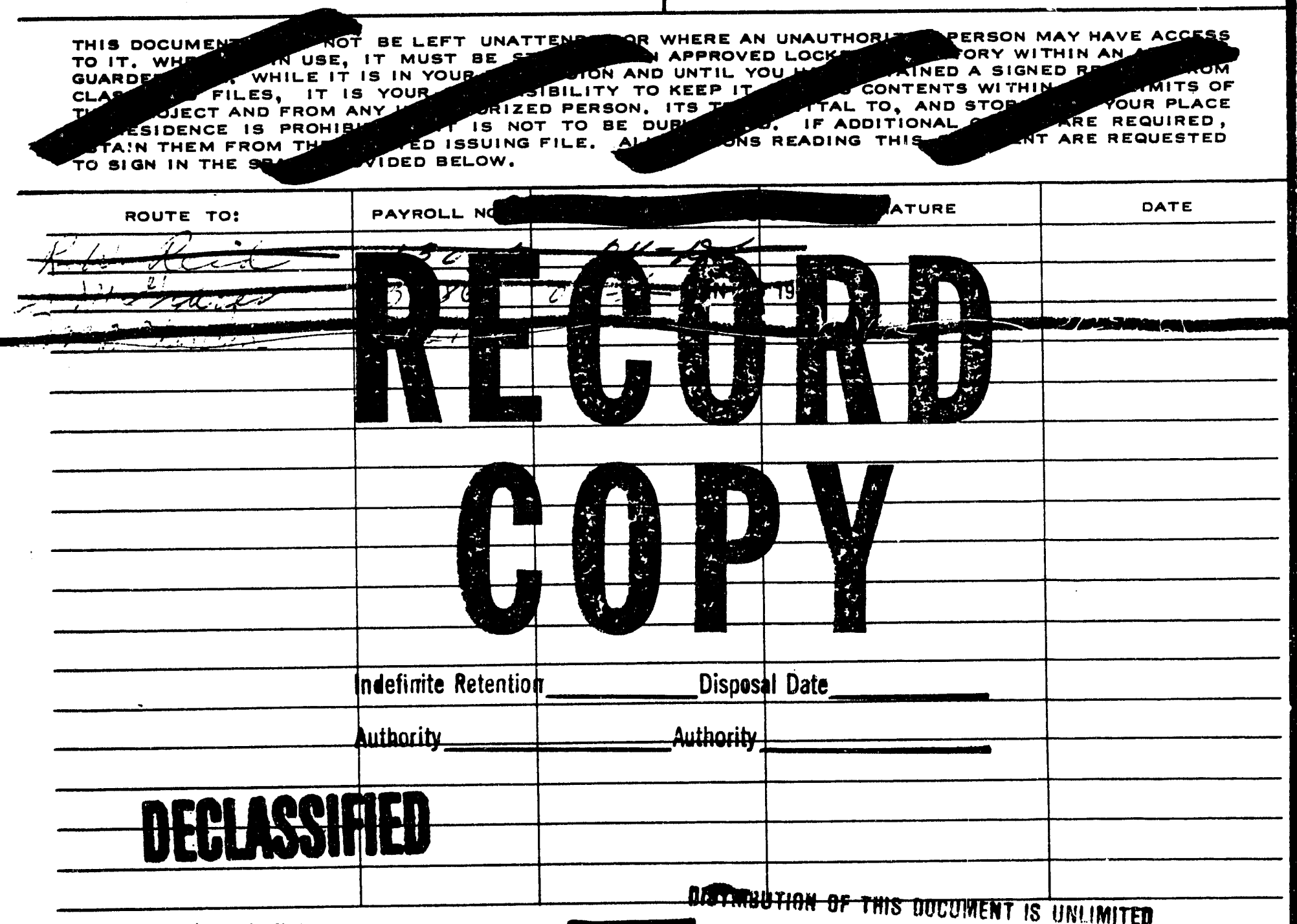

C-3195-D $(11-54)$ AEC.er nienLANo. wash. 


\author{
1. RS Bell \\ 2. JT Baker \\ 3. JL Benson \\ 4. RV Bowersock \\ 5. RI Call \\ 6. AB Carson \\ 7. WH Clark \\ 8. $\mathrm{JH}$ Curtiss \\ 9. RL Dickeman \\ 10. GC Fullmer \\ 11. $\mathrm{RH}$ Gay \\ 12. OH Greager \\ 13. TM Hall \\ 14. WM Harty \\ 15. WK MacCready \\ 16. JC Major \\ 17. D Marinos \\ 18. JS MaMahon
}
19. JHM Miller
20. CA Munro
21. JF Music
22. R Nilson
23. CA Priode
24. RW Reid
25. LP Reinis
26. GJ Rogers
27. ER Budock
28.' W Seeburger
29. HG Spencer
30. $P$ Thompson
31. RE Trumblè
32. WW Windsheimer
33. EC Wood
34. Extra
35. 300 Files
36. Record Center

\section{ALTERNATIVE ACTIONS ON THE K STACK PROBLEM}

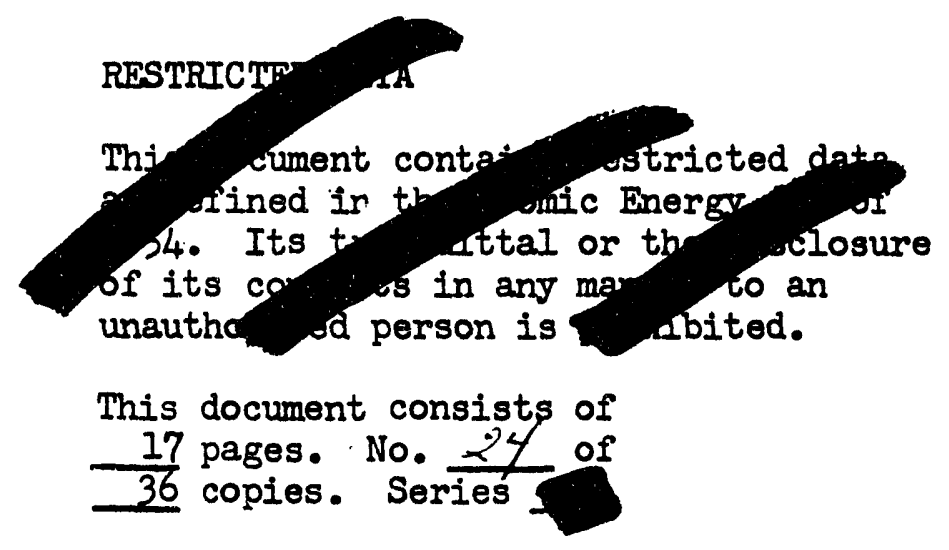

\section{PREITMTINAFY REPORT}

This report was prepared only for use within General Electric Company in the course of work under Atomic Energy Commission Contract W-31-109-Eng-52. Any views or opinions expressed in the report are those of the authors only. This report is subject to revision upon collection of additional data.

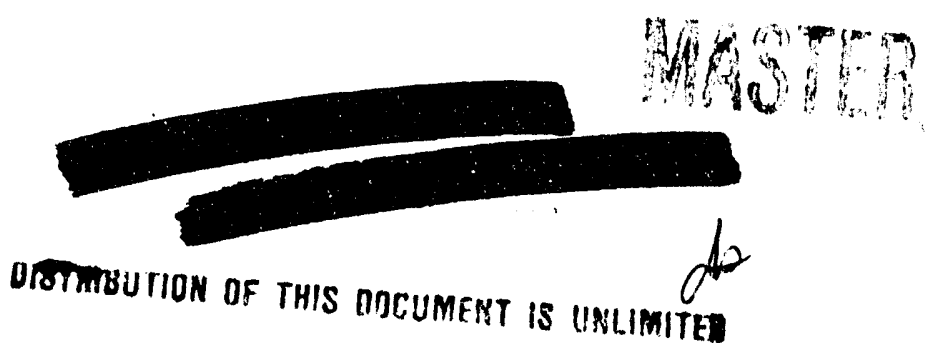




\section{ALTERNATIVE ACTIONS ON THE $\mathbb{R}$ STACK PROBLEY}

\section{INTRODUCTION}

On June 6, 1958, $\mathrm{KW}$ Operations had HCR Channel \#16 borescoped to determine why this rod could not be inserted on May 3. Observations revealed 3X balls in the channel and horizontal separation between graphite blocks ranging from $\frac{1}{2}$ inch to $2 \frac{1}{4}$ inch. The separations were noted only in the first fifteen feet in from the outer skin and in the last five feet of the channel. No significant deterioration of the graphite, such as breakage, was observed. As a result of these findings and past operational difficulties with certain HCR's at both KE and KW Reactors, a program of measurements $(\bar{I}, 2)$ is in progress to determine the extent and cause(s) of the stack displacements. From measurements and observations so far obtained, the following conclusions may be drawn about separations at locations of consequence to the loss of $3 X$ balls from channels:

Side to side horizontal separations totaling two to three inches have been observed at both reactors. The significant separations lie outside of the VSR pattern and in the lower half of the stack. The VSR pattern does not include the six outer ball 3X channels. There are probably a few small separations ( $<\frac{1}{2}$ inch) at the outer VSR's. There are probably no separations large enough to admit balls on inner VSR channels, i.e. VSR's inside the outer front to rear rows of VSR's.

These conclusions can not be considered fully reliable, but no information obtained to date refutes them.

A team was established on 9-17-58 to evaluate and provide information on alternate courses of action for elimination or alleviation of the problem. This report contains the information and recommendations developed by the team.

(1) HG Spencer, Determination of Graphite Stack Distortion, 8-27-58, (Conf.-Undoc.)

(2) EC Wood, K Reactor Graphite Problem, 9-19-58, (Conf.-Undoc.) 
II. SUMMAPY

Various alternate courses of action for elimination or alleviation of the problem are presented. The various costs, including development and installation costs, annual operating costs and required outage time for the various alternates, are sumarized in the table on page 4 . In some cases, cost data not specifically presented in the Discussion were used in the formulation of the Table. However, in all such cases, the values in the table are consistent with the cost estimates in the Discussion.

All of the estimates were prepared in a very few days and in many cases. information adequate for bases was not available. Therefore, large errors may exist. Information on possible variance of many estimates may be found in the Discussion.

III. RECOMENDATIONS

1. The safety circuit changes proposed should be made as soon as practical.

2. A remotely operated locking device for $3 \mathrm{X}$ hoppers should be developed, tested and installed.

3. The ceramic ball development program, (3) with alternate poisons, recently initiated for NPR and for present piles after installations of zirconium tubes, should be accelerated and expanded as necessary for possible early application at the K Reactors.

4. Work to determine the feasibility and method of pushing the stacks back toward the original position, and holding them there, should be authorized.

5. The remaining altematives, namely plugging cracks and vertical and horizontal sleeves, would all require considerable design and development and/or testing work. One view of the team is that the actions recommended in 1,2 and 3, above, and the possibility that a feasible method will be developed and, later, successfully applied in restoration of the stacks (assuming recormendation 4, above, is followed), all combine to give sufficient reason to authorize no expenditure of design and development effort on the remaining alternatives, at this time. Later information or indication that restoration and restraint would not be feasible would be justification for initiation of efforts, according to this view.

(3) Letter, RR Henderson from GJ Rogers, Alternate 3X Ball Materials, 9-26-59.

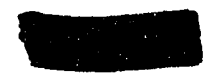




$$
\begin{array}{ll}
\mathrm{HW}-57518 \\
-4- & 9-29-58
\end{array}
$$

ALTERNATIVE ACTIONS - ESTTMATED COSTS AND LOSSES FOR BOTH K REACTORS (Dollars In Thousands)

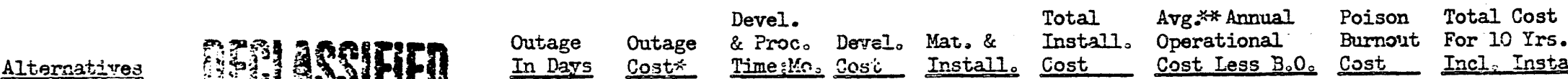

1. Do nothing

$\begin{array}{lll}\text { Do nothing } & \\ z_{0} \text { Present eracks; 0ld circuitry } & 6.6 & 600 \mathrm{~A} \\ \text { b. Present cracks NoC. } & 1.1 & 100 \mathrm{~A}\end{array}$

co Maxo craciks; NoC。

2. Ceramic - Cd Balis

a. Ien non-VSR hoppers; $\mathrm{N}_{c} \mathrm{C}_{0}$; pres.

b. All yertical channels: NoCos max. cracks

3. HCR Sleeves (Iower ten, only)

3. $\mathrm{N}_{0} \mathrm{C}_{0}$; onij; present cracks

b. NoCo $\xi$ cer.-d balls, 10 outer

channels; pres. cracks

c. NoU; cer, fd balis-all hoppers; max. cracks

4. Vertical Channel Sleeves

\section{to 16 channels $N_{0} \approx$ pres。 cracks}

b. 30 channels; N.C. max。 cracks

1.1

100

$100 \mathrm{~A}$

\& Proc。 Derrel. Mat, \& Install. Operational

5. Fijgging Cracks

j. Fres。Cracks; Outer six channels;

b. Hore cracks; 16 channels; NoC。 16

$\therefore$ Hax。 cracks; 30 channeis; Noc $\quad 30$

Time:kno Cosi Install.

Cost Cost Less $\mathrm{B}_{0} \mathrm{O}_{0}$ Cost

Incl. Install

6. Restore Stack (against bails); N,C (It 10

\begin{tabular}{|c|c|c|c|c|}
\hline $\begin{array}{l}2340 \mathrm{I} \\
2340 \mathrm{I}\end{array}$ & $\begin{array}{l}9-12 \\
9-12\end{array}$ & $\underset{n}{\left(\operatorname{Irc} c_{.}\right)}$ & $\begin{array}{l}138 \\
178\end{array}$ & $\begin{array}{l}2478 \\
25 i 8\end{array}$ \\
\hline $2340 \mathrm{I}$ & $9-12$ & $n$ & 342 & 2682 \\
\hline $1800 \mathrm{I}$ & $\begin{array}{l}\text { Consid- } \\
\text { erable } \\
\text { " }\end{array}$ & $\begin{array}{c}\text { (Not } \\
\text { Inc.) } \\
n\end{array}$ & 408 & 2208 \\
\hline $3060 \mathrm{I}$ & $\pi$ & 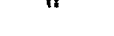 & 773 & 3833 \\
\hline $540 \mathrm{I}$ & $5-9$ & 10 & 29 & 579 \\
\hline $\begin{array}{l}1440 I \\
2700 I\end{array}$ & $\begin{array}{l}5-9 \\
5-9\end{array}$ & $\begin{array}{l}10 \\
10\end{array}$ & $\begin{array}{l}57 \\
96\end{array}$ & $\begin{array}{l}1507 \\
2806\end{array}$ \\
\hline $\begin{array}{l}900 \text { I } \\
\text { tion) }\end{array}$ & 6 & 30 & 40 & 970 \\
\hline
\end{tabular}

is assumed that $\mathrm{ng}$ cracks are formed after restoration)

1050
550
-2340

$\begin{array}{rr}480 & 10,980 \\ 480 & 5,988 \\ 1,440 & 24,848\end{array}$

* At $\$ 90,000$ a day. "A" stands for annual; "I" stands for installation.

After several drops

Assumes channel will never have to be plugged more than once; therefore is not a valid ten-year cost unless further ieparation after * This would have to be increased by the cost of an installation to hold the stack in the restored position - estimate not arailabie.

HOTE: N.C. is installation of proposed Ball 3X circuitry and locking system. 
The other view is that the possible consequences of ball drops and the uncertainty and timing associated with ceramic balls and with stack restoration and restraint, justify a reasonably aggressive design and development effort on all the remaining alternatives. The effort would produce firm designs and cost estimates and detailed plans for installation methods. The team is uncertain about the relative merits of these two views; strong reasons why one view was preferable to the other were not discovered. Therefore, the team does not wish to make a recommendation on the remaining alternatives.

IV. DISCUSSION

\section{A. Cost of No Action}

Before discussing the possible courses of action, it appears worthwhile to examine the cost if no action were taken other than the removal of the balls from HCR's made inoperable by any ball drops.

Data and assumptions used were as follows:

1. The tube traverse data and the borescope data from the $K$ Reactors were analyzed and the voids adjacent to the fringe ball channels were calculated to have a volume of 7.6 cubic feet on each side at the present time. This is a conservative estimate. We would not be surprised if the volume were 50 per cent of this amount, or less.

2. It was estimated that about $1 / 15$ of this volume or approximately 0.5 cubic feet of balls could be trapped in the reactor on each side $i \bar{n}$ the presently existing gaps, on the next ball drop. The following ball drop was assumed to permit half this amount to enter, and so on, so as to eventually approach a total amount of two cubic feet of balls for present separations.

3. One cubic foot of balls in the cracks was estimated to weigh 70 per cent of one cubic foot of steel, or balls weigh 340 pounds per cubic foot.

4. The cost of removing balls from a HCR channel is $\$ 625$ for manpower and materials and 20 hours outage time. $(4)$

(4) Personal communication from L. P. Reinig. 
R. S. Bell

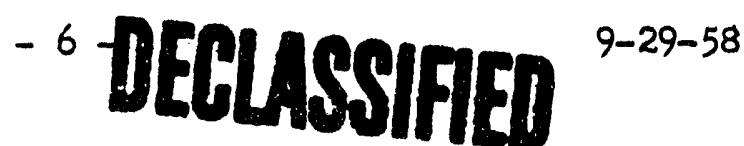

5. It was assumed that in any ball drop, balls would likely enter about four HCR channels. Since more than one channel would need to be cleaned out and since other productive work could be done during the outage, the actual outage time per channel was estimated to be 10 hours. At the present time only two HCR channels at one reactor (KW) have been observed to contain balls. Other channels may also contain balls and if the reactor continues to expand, additional HCR channels may have balls admitted to them.

6. Outage time is worth $\$ 3750 /$ hour at a $\mathrm{K}$ Reactor.

7. The cost of burning out the boron in the balls trapped in the reactor would be $\$ 350$ per $1 \mathrm{~b}$ of balls. (5)

8. The cost of neutrons absorbed by the steel would be $\$ 1.50 /$ day/lb
of balls.

9. In the past there has been an average of two ball drops per year per reactor at the $K$ Reactors. This rate was assumed to continue unchanged. The drops were assumed to occur at the beginnings of the second and fourth quarter of the year for the purpose of calculating the loss to neutron absorption in the steel. However, the full cost of boron burnout was charged at the time of each drop. The boron burnout cost is actually incurred at a declining rate which becomes essentially zero one year from the date of ball entry.

With the above estimates and assumptions, the total cost for one reactor for the present size separations during the first year and following years would be as follows:

YEAR

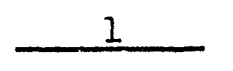

2

Each Following

costs

$\begin{array}{lrrrr}\text { Boron Burnout } & \$ 179,000 & \$ 45,000 \Sigma & \text { For all succeeding years- } \$ 15,000 \\ \text { Steel Absorption } & 115,000 & 224,000 & \$ 225,000 \\ \text { HCR Cleanout } & 300,000 & 300,000 & 300,000 \\ & \$ 59,000 & & \$ 569,000 & <\$ 540,000\end{array}$

For present separations and ball drop frequency, the calculated costs are probably high, perhaps by a factor of two.

(5) Letter, R. Nilson to HG Spencer, K Graphite Problem, 9-24-58, (Conf.-Undoc.) 

R. S. Bell
$-7-$
$9-29-58$

Tou little is known about the cause of the present separations to do more than speculate about what will happen to them in the future. However, a reasonable and conservative assumption would be that if ball drops continue (and perhaps if they don't), the separations will grow in size and extent. We have guessed that the shields would limit the total possible amount of balls to about six cubic feet, which is a factor of three increase over that estimated for the present separations.

\section{B. Actions To Reduce Ball Drops}

Before considering actions to prevent (or reduce the consequences of) balis entering the stack when balls are dropped, we will discuss actions to reduce or prevent ball drops. It appears desirable to us to place considerable immediate emphasis on these actions, because, as will be seen later, actions to keep dropped balls out of the stack would, by-and-large, require considerable time to effect. Furthermore, it is within the realm of possibility that these dropprevention actions could result in balls never being dropped. As will be seen later, this applies particularly to the outer six channels that do not contain VSR's, which also are now the only ones where significant separations exist.

For prevention of ball drops, the changes in equipment and Process Standards enumerated below are proposed. We cannot guarantee at this time that all of these changes will be permissible because Process Standards cannot be approved in advance. However, agreement on permissibility has been obtained at all lower levels of interested Research And Engineering Management.

The changes are:

1. The $3 \mathrm{X}$ system would be split into two parts -- an inner system and an outer system. The outer system would include the outer six channels and the inner system would be composed of the remainder. At the present time, it is believed almost certain that this split would be permissible. Furthermore, it may be found possible to enlarge the outer system. Definite information on how to make the split is being obtained by computer calculations. Results should be available by October 1, 1958. 
2. The outer system would be bypassed except during extended outages and from critical on cold startups until, at most, 24 hours later. The length of time that the system must be unbypassed is also being determined with the aid of computer calculations and results should be available by October 6, 1958. It would be permissible to develop and install a remotely or manually operated positive locking system on the outer system to prevent drops by personnel error or certain types of component failure. It has not yet been decided whether or not the outer system could be locked out during an extended outage. It may be necessary to require unlocked hoppers and provision for a manual trip from shortly after extended outage shutdowns until critical as well as during the period after critical on cold startups. However, it is definitely agreed that locking would be permissible at all other times.

3. The trips required on the outer system from critical to not more than 24 hours later on cold startups would be a manual trip, a water pressure decay trip and an ELP trip, as is presently required for the entire system.

4. The inner system would have to be in service as now required for the entire system. Water pressure decay trips and ELP trips would be required as at present. In addition, we consider it necessary to include a seismoscope -- flux decay system as proposed by R. W. Hooper $(6)$ in lieu of a seismoscope trip. This seismoscope flux decay system consists of parallel contacts on the seismoscopes and on 2 Beckman low trip. There would also be a seismoscope trip on the \#1 Safety Circuit. Thus, a seismoscope trip would not drop balls unless the flux had not decayed by a specified amount in a specified period.

5. In conjunction with these changes, a revision in testing requirements now in Standards would be necessary. We do not believe it is reasonable to eliminate all testing. The several alternative methods $(7)$ of testing, all agreed to be permissible, are as follows:

(6) Letter, RW Hooper to RE Trumble, Improved Earthquake Protection - All Reactors, 9-12-58.

(7) Letter, IM Hall to HG Spencer, Elimination Or Revision Of The Functional Testing Procedure For The Ball 3X System, 9-19-58 


\section{DECLSSSFFED}

HWW -57618

R. S. BeII

a. Provide ball hoppers above the top of the reactor as at all old areas. Although cost of this method was not determined, it is considered to be so high compared to others as to be reason for discarding this method.

b. Use of a full-length temporary channel sleeve. Total cost of this system is estimated at $\$ 20,000$ for a full test plus about four outage hours per hopper assuming several are tested in succession.

c. Vacuum balls from hopper prior to test. Contamination problems with this method would be less than that for the sleeve but radiation exposure would remain high. Costs are estimated to be $\$ 7,000$ for a full test plus two hours per hopper if a number of hoppers are tested in succession.

d. Crack the hopper gate and let all balls flow down channel and on out. The crack would be adjusted so that balls would not stack in the channel. Functional tests would be performed on the empty hopper. This method does not preclude the entrance of a few balls into the stack, however, the number would be expected to be small - probably no more than ten pounds per full test.

Cost of the proposed safety-circuit changes would be as follows:

Hopper locking devices

Outer system safety circuit

( 6 hoppers assumed)

Seismoscope - flux decay for inner system

TOTAL
(Estimate not made but not high)

1700

500

The frequency of ball drops in the inner system would be reduced little, compared to the old system including the seismoscope. Perhaps a 30 to 50 per cent reduction should be expected. The frequency of drops of the outer system should be greatly reduced. The outer system would be in the safety circuit only two to seven per cent of the time, and the number of tripping devices during this time would be two-thirds that of the old system. Thus, if every time unit affords an equal probability, the frequency would

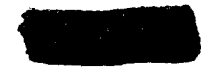


HW- 57618

be a factor of 10 - 30 below that previously experienced. This would mean a frequency of about once every 5 to 15 reactor years, based on the past experience of two per reactor year at the $K$ Reactors. The assumptions above are probably too optimistic: startup is probably a more vulnerable period than equilibrium operation; there are other causes of drops (personnel error, power failure) which are not affected, although the locking devices should eliminate the majority of drops due to these. Thus a conservative estimate would be perhaps a reduction by a factor of $6-12$. This would be a frequency of one drop every three to six reactor years in the outer system.

Maintaining all balls on manual trips, only, is not, in our opinion, an action that could be permitted. It is our understanding that even if HAPO management wanted this done, AEC and ACRS approval would have to be obtained.

\section{Alternative Actions To Keep Balls Out of Stack Or Reduce Consequences}

\section{Replacement of Present $3 X$ System (5)}

The original intent of the Ball $3 \mathrm{X}$ system was to provide a backup to the vertical safety rods, the reasoning being that in the event of a disaster in which the stack was so seriously distorted that VSR insertion was not possible, a fluid-like system would have a high probability of getting into the pile. Any replacement system must have this same characteristic and in addition, of course, the required strength. For the sake of completeness, the following discussion covers various replacement systems or modifications of the present system which do not meet the above requirements in addition to those that do.

\section{a. Liquid or Gas}

Both gases (probably $\mathrm{BF}_{3}$ ) and liquids would have to be contained in some type of tube. If containment tubes were put in the reactor the existing ball system could be used as well. Further, a tube leak with gas or liquid could be disastrous, rendering the reactor useless, while a leak with balls would only create a costly nuisance of "burning" the balls out during operation. A gaseous system would also have the disadvantage of requiring pressurization to achieve and maintain the required poison strength confined in tubes. Therefore a gas or liquid system is not a suitable replacement.

(5) Letter, R. Nilson to HG Spencer, K Graphite Problem, 7-24-58, (Conf.-Undoc.) 


\section{b. Horizontal Rods}

(1) Accelerated - The present problem is total control rather than control response time. The VSR's provide sufficient poison to meet the speed of control requirement. Further, if the V.SR's would not go in, there is serious doubt if horizontal rods could be relied on.

(2) Horizontal Rods In Test And Octant Holes - Horizontal rods do not place the poison selectively where needed, vis., the near and far side fringe enrichment zone. Also their effect would be shadowed by the existing horizontal rods. The octant holes do not penetrate into the active zone of the reactor and thus would be virtually useless for control. Even with full utilization of the test holes, and drilling 06 the octant holes, it is doubtful that the total increase in strength would even approach that if ine outer ball channels in the fringe-enricised dry reactor.

\section{Modifications To Present System (5)}

\section{a. Larger Balls}

Boron steel balls up to one inch in diameter for the outer six ball channels would materially aid in reducing balls getting out of the channels into the stack. However, existing ball sizes are even troublesome in that plugging has made ball removal difficult. It is thus very likely that larger balls could hang up by bridging either in the openings in the ball hopper or in the removal valve at the bottom of the pile thus causing a real problem of getting the balls in and out of the channel. For this reason larger balls would probably create more problems than they would solve.

\section{b. Irregular Shaped Balls}

The spheroidal shape of the present balls aids greatly in the movement within the pile. Irregular bits of boron steel would reduce significantly the transport of balls within the reactor, but on the other hand the probability of the ball channel choking up preventing ball removal becomes very great. Therefore, this is not a good alternative.

(5) Letter, R Nilson to HG Spencer, K Graphite Problem, 9-24-58, (Conf.-Undoc.) 
c. Ball Chains

The conceivable methods of tying the poison elements together in some type of chain zuffer from the same disadvantage as the irregular shaped balls. That is, flow of the poison into the reactor would probably be less efficient. Further the stacking of poison elements in the channel might not fill the available spaces which is necessary to achieve maximum strength from the column.

d. Alternate Balls And Ball Poisons

One of the principal objections to losing balls in the reactor stack is the cost, neutron-wise, of burning out the poison. The neutron capture comes from two sources: 1) the principal poison (boron at present) and 2) the carrier (steel at present).

The additional cost of the neutrons lost to the iron in the steel has been calculated to be about $\$ 1.50$ per pound of balls per day. This represents the rate of loss of neutrons which will remain essentially constant for the life of the reactor.

Most of the ceramic materials have small neutron capture cross sections compared to iron. The neutron cost of the ceramics material of the ceramic impregnated with poison should therefore be negligible compared to the steel. If aluminum, silicon, and oxygen are the only constitutents (other than the poison) this cost would be reduced to about one per cent of the cost of steel per day per equivalent volume of steel balls.

The number of poison atoms which must be in the balls per unit volume is inversely proportional to the microscopic cross section. This is necessary to give a column of balls a constant strength in the reactor. The cost of "burning" out all the boron 10 in one per cent boronsteel balls has been calculated to be a total of $\$ 350$ per pound of balls. This cost would be incurred over one year at current power levels.

If a poison with a higher cross section than boron 10 were used, fewer atoms per unit volume would be required. Thus fewer neutrons would be lost to burning out the poison in balls lost in the reactor. Two examples of

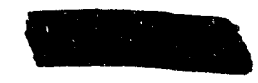


attractive replacements for boron are cadmium or gadolinium. The cost of burning out the cadmium would be about 15 per cent that of boron and gadolinium would be about 3 per cent that of boron.

From the above discussion it seems obvious that a potentially attractive ball $3 \mathrm{X}$ modification is the use of ceramic nonboron balls in those ball channels where leakage into the gaps in the reactor is possible. The outer six channels in the $K$ Reactors seem to be of most concern, and since these are not provided with VSR's, the problem of ball breakage by the VSR's dropping on the balls i.s not a problem. There may be radiation and contamination problems, also, which could seriously affect the feasibility of new ball materials. The use of ceramic balls eliminates most of the cost of leaving the lost balls in the reactor. This coupled with other alternatives such as sleeves for the HCR channels to keep balls out of these holes, or perhaps only the proposed safety circuit revisions to reduce the cost of HCR channel clean-out to a low annual cost should result in a relatively small annual cost. For example, the table on page 6 in cost of doing nothing (for present size voids; would be as follows, assuming ceramic-cadmium balls could be used in the channels not containing VSR's (10 total). and further assuming that significant cracks do not open around VSR's (or if they do, that a satisfactory ceramic ball could be developed for that location).

YEAR
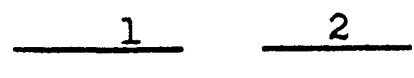

Each Following

cosTs

$\begin{array}{lrrr}\text { Cadmium Durnout } & \$ 27,000 & \$ 6,800 & \$ 2,200 \text { Sfor all } \\ \text { Carrier Absorption } & 1,150 & 2,240 & 2,250 \\ \text { HCR Cleanout } & 300,000 & 300,000 & 300,000 \\ \text { TOTAL (rounded) } & 328,000 & 309,000 & 304,000\end{array}$

This is still a high cost because of the HCR costs. However, a factor of six reduction, the minimum factor predicted under $\mathrm{B}$, above, would reduce the costs to $\$ 78,000, \$ 59,000$ and $\$ \$ 4,000$ for the first, second, and succeeding years, respectively. 
Development and testing of replacement ceramic-non-boron balls is therefore recommended. A very rough estimate is that these balls would cost about five dollars per pound and that about 400 pounds would be needed per hopper.

\section{HCR and VSR Sleeves ${ }^{(8)}$}

Graphite sleeves cannot be used in either the HCR of ball channels unless the channel is enlarged by some form of drilling and milling tool. Enlarging the channel is considered as not feasible at this stage from the aspect of tool development, reactor outage time and personnel exposure time. Reducing or changing the cross sectional shape of the control rods is, also, not considered as feasible at this stage. These two approaches may prove to be feasible after a more exhaustive study than permitted in the short time available.

It appears that if a sleeve is to be used in the HCR it must be a cooled metal sleeve. Since water is available to the rods, the sleeve, a half circle annular shape, could also be water cooled. A new-designed step plug, to accomodate the water connectors, would be required. It is estimated that this work would require approximately $\$ 100,000$ per area with a 20 day outage per area. Nine to twelve months of design development, testing and procurement would be required. This cost is for all HCR's. It is likely that only half of them would require sleeves. In this case, the total cost would be $\$ 65,000$ and 13 days outage per area.

A metal sleeve in the vertical channels is feasible providing some means of straightening the channel is developed (forcing or milling out the obstmucting blocks.). Sleeves will reduce the space allowed for $3 \mathrm{X}$ balls and may require a change in rod shape to prevent the ball.s from bridging and not dropping. Since, testing of the balls and sleeve and existing rod or new shape plus development of a channel aligning tool will require significant time, this scheme is not considered as favorable for immediate action, but is recommended for long term planning if prevention of ball entry into the stack is a must.

(8) Letter, ER Rudock to HG Spencer, HCR And VSR Sleeves - Graphite Separation 9-23-58. 
The use of gas for a coolant was not considered because of the additional equipment costs for compressors and manifolding. The choice of sleeve material (aluminum or zirconium) is not considered as a limiting factor. Both would require cooling. The final choice would be made after additional study.

It is estimated that sleeves on all vertical channels would requi :e $\$ 500,000$ to $\$ 750,000$ per area (not counting development costs) and 20 to 25 days outage time. It might be found reasonable to put sleeves on only 16 channels. This would cost about $\$ 200,000$ and 10 days outage per area.

\section{Plugging The Cracks (9)}

The most promising material evolved during the brief time available for investigation appears to be a graphite or carbon foam. This material lends itself to application much more easily than other materials considered, e.g., carbon wool.

The material would probably be applied in the form of a paste which would expand upon application of heat. The expansion would exert essentialiy no force on the surrounding graphite. Should graphite continue movement, the material would crush easily, allowing free movement of the graphite. The bonding agent would be a resin or tar similar to that used in manufacture of the existing graphite. Some flaking will occur from ball contact with the material; however, it is believed that ample blocking will be provided to prevent any appreciable quantity of balls from entering the cracks.

Development of the foam material will require at least three months and application testing two to six additional months. It is estimated that the material would be available five to eight months after development authorization.

Costs are estimated as follows:

Development and testing

Equipment Application to VSR Channel Application to HCR Channel

$$
\begin{aligned}
& \$ 10,000 \\
& 4,000 \\
& 1,400 \text { each } \\
& 1,600 \text { each }
\end{aligned}
$$

(9) Letter, CA Munro to HG Spencer, Plugging Cracks In K Area Graphite Stack, 9-23-58. 


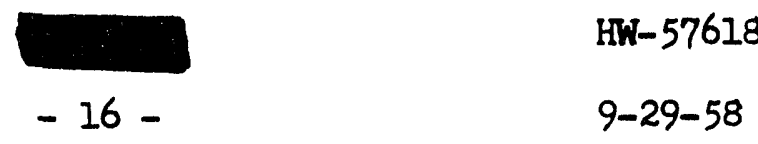

Total cost for both the vertical and HCR channels in both reactors would be approximately $\$ 220,000$. This would include all costs excluding reactor downtime. Application would require twenty days reactor outage time assuming application during one outage. If the task were to be accomplished during scheduled outages the time would be significantly extended. However, if vertical channels are sealed there would be little need for sealing of the HCR channels. Application to the outer six ball channels would probably be all that would be needed for the present separations. Total cost for this job is estimated to be $\$ 31,000$ plus six days outage for the total job at both reactors. Additional vertical channels would cost $\$ 1,400$ each plus an additional half day of outage time.

\section{Restoring Moderator Position}

D. Marinos and G.J. Rogers have attempted to evaluate the feasibility and costs associated with attempting to restore the moderator stack towards its original position by applying force to the near and far sides of the graphite packing.

They conclude that this approach will require considerable development and testing to demonstrate technical feasibility. The preferred approach at present would involve inserting deflated inflatable bags (air mattresses) through step plug openings and locating them in the remaining gap between the side thermal shield blocks and the side of the graphite. It is presumed that a number of small bags would be used because of the restricted size of the shield-graphite gap in the affected region. Each bag would be connected to an air pressure supply by a flexible hose or tube. Air pressure could be applied to bags singly or in groups to inflate them and thus apply restoring force to the graphite.

Preliminary study has shown that a unit pressure of about $1.5 \mathrm{psi}$ is sufficient to overcome friction between layers and cause motion of the graphite. This value neglects the additional restraint offered by graphite keys and any $3 \mathrm{X}$ balls which may be trapped in existing gaps between blocks. The side $B$ shields are strong enough to restrain the force developed by a 1.5 psi pressure over a large area, probably at least the lower third of the entire side. 
Because of present uncertainties in the actual restoring force requirenents, a period of six months of development and testing of the method on mockups is believed to be required, at an estimated cost of about $\$ 30,000$ for manpower and materjals. During this testing, results of force required would be checked against shield strength to establish technical feasibility.

If it were determined that the method is feasible, application to a reactor should be relatively inexpensive. Costs would involve manpower for step-plug removal and to insert the bags plus material cost of the bags. Assuming 1500 square feet of bags are required at $\$ 7.00$ per square foot gives under $\$ 14,000$ material cost. Manpower costs are taken as fifteen manhours to remove and replace each step-plug for 50 step-plugs, totalling \$6,000 per reactor; and insertion of 50 bags at four manhours each for a total manhour cost of about $\$ 3,000$. It is guessed that total shutdown time might be about five days per reactor.

Methods of preventing further outward motion once the restoration is made are presently under study by $D$. Marinos and G.J. Rogers. Information suitable to report is not jet available.

\section{ACKNOWLEDGEIENT}

Members of the team which developed the information in this document were R.L. Call, T.M. Hall, D. Marinos, C.A. Munro, R. Nilson, L.P. Reinig, G.J. Rogers, E.R. Rudock and H.G. Spencer, Chairman. The team also wishes to acknowledge the contributions of R.V. Bowersock, A.G. Dunbar, R.R. Henderson, G.F. Owsley, and D.E. Simpson.

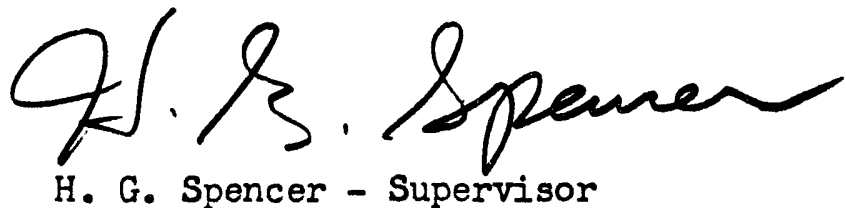

H. G. Spencer - Supervisor

Process Analysis Operation

Eesearch \& Engineering Operation IRRADIATION PROCESSING DEPARTMENT

HGS:ga 
DOC I
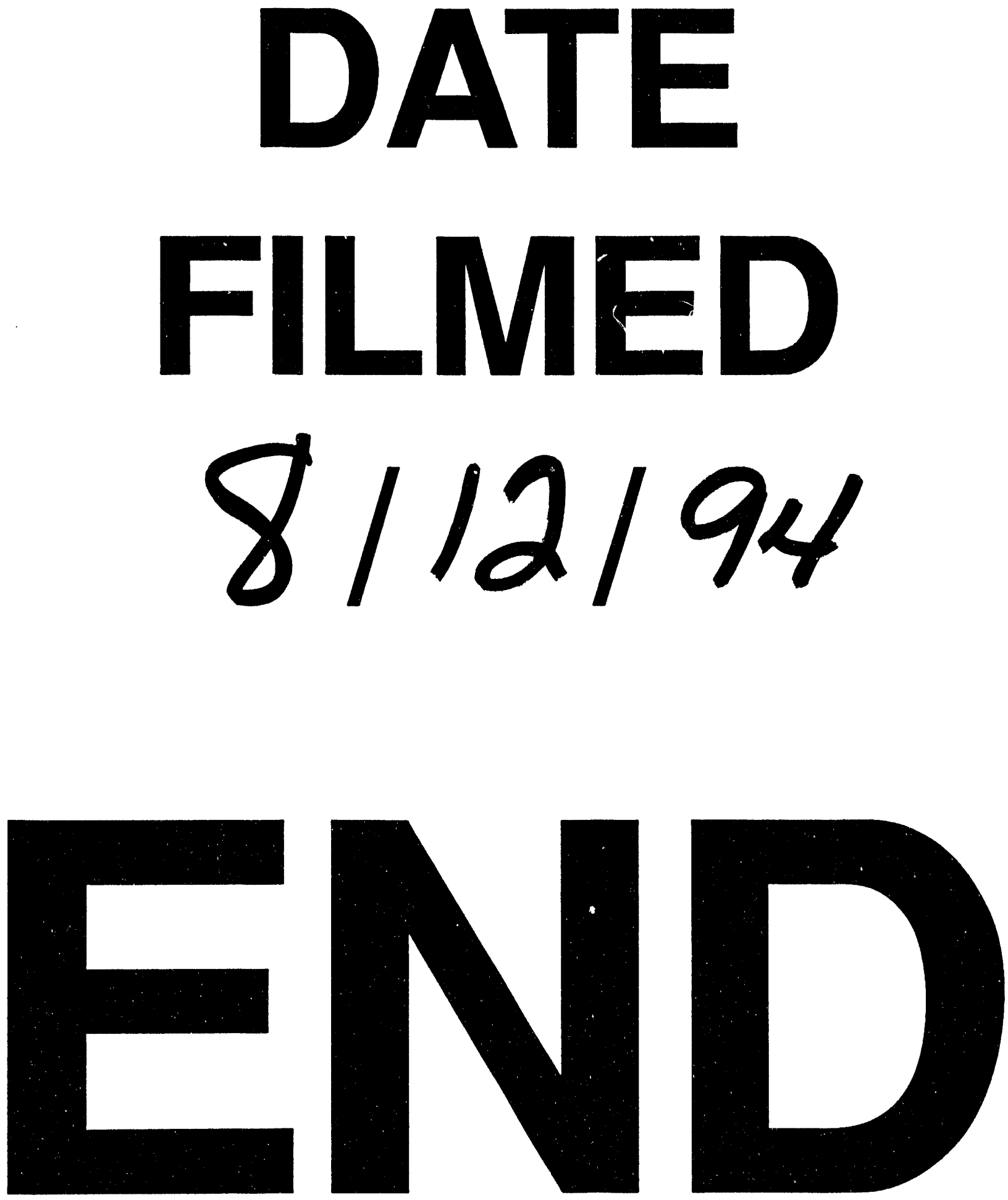


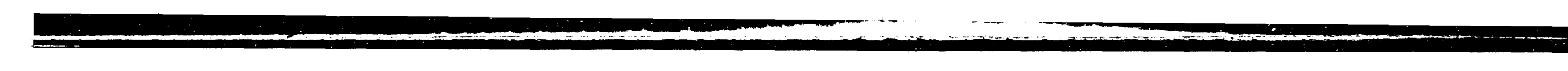

